Original Research Article

\title{
Effect of chronic administration of nicorandil (a potassium channel activator) on body weight of two different experimental animal species
}

\author{
Sanjib Das ${ }^{1 *}$, Kusai M. Alsalhanie ${ }^{2}$, Samal Nauhria $^{2}$, Atindra N. Datta ${ }^{3}$
}

${ }^{1}$ Department of Medical

Pharmacology and Therapeutics,

${ }^{2}$ Department of Medical

Pathophysiology, Windsor

University School of Medicine,

Cayon, St. Kitts, West Indies

${ }^{3}$ Department of Anatomical

Sciences, Medical University of the Americas, Potworks, Nevis, West Indies

Received: 28 April 2017

Accepted: 24 May 2017

\section{*Correspondence to: \\ Dr. Sanjib Das, \\ Email: dr_sanjib100@ \\ yahoo.com}

Copyright: (C) the author(s), publisher and licensee Medip Academy. This is an openaccess article distributed under the terms of the Creative Commons Attribution NonCommercial License, which permits unrestricted noncommercial use, distribution, and reproduction in any medium, provided the original work is properly cited.

\begin{abstract}
Background: Potassium channel openers (Nicorandil being the prototype) are a distinct class of drugs, used in the management of chronic stable angina pectoris. Obesity is a frequent co-morbid condition and also a risk factor for angina pectoris. Anti-obesity drugs are used more frequently these days than ever before. Therefore, it is more likely that physician would be prescribing at least 2 or more drugs while treating such comorbid conditions. This generates a need for the development of a new drug which would work against both angina and obesity. The resultant effect would be a reduction in the cost burden, incidences of side effects and possible drug- drug interactions as compared to multidrug therapy. The purpose of this study is evaluating the chronic effect of Nicorandil (graded doses) on the body weight in 2 different species of animals i.e. rabbits and mice.

Methods: In this study, 30 experimental animals of each species were selected. Pretreatment weight (Mean body weight \pm SEM) of each group were recorded and compared with the post-treatment values of the respective group in every week up to a period of 4 weeks. The route of administration was an intraperitoneal injection.

Results: Chronic administration of nicorandil causes a significant reduction in body weight at moderate to high doses in both species of the study group. ( $p$ $<0.05)$.

Conclusions: Body weight reducing, an effect of nicorandil in animals, if established in human, could enhance its acceptability in obesity with various ischemic heart diseases including angina.
\end{abstract}

Keywords: Body weight, Chronic administration, Graded dose, Nicorandil, Potassium channel activator

\section{INTRODUCTION}

Potassium channel openers/activators are a distinct class of drugs used in wide variety of clinical conditions. These drugs are available in the global pharmaceutical market for more than two decades. Nicorandil being the prototype of this class is used for the management and long-term prophylaxis of chronic stable angina pectoris. ${ }^{1-4}$ It is also believed that nicorandil has potential use in the management of hypertension of various etiologies, myocardial salvage in myocardial infarction
(MI), congestive heart failure(CHF), alopecia, bronchial asthma, urinary urge incontinence, premature labor, peripheral vascular diseases (Raynaud's, cerebrovascular) and penile erection disorders. ${ }^{5}$

It is a novel derivative of Nicotinamide that possesses a terminal nitrate group chemically known as N (2-hydroxy ethyl) Nicotinamide Nitrate.

Nicorandil has been described as a hybrid between nitrate and potassium channel activators as they have a dual 
mechanism of action involving both components. It causes vasodilatation of coronary and systemic arteries in the following way.

A nitrate mechanism involves stimulation of guanylyl cyclase that increases cyclic GMP production and consequently decreases cytosolic free calcium in vascular smooth muscles. cGMP also causes dephosphorylation of myosin light chain and makes them inactive to bind with actin and prevent contraction. ${ }^{6}$

Decreased sensitivity of the ATP-dependent potassium channel increases the flow of potassium from the sarcolemmal potassium channel. This causes a hyperpolarization that closes voltage - dependent calcium channels in the cell membrane and increases calcium efflux through the sodium channel exchanges.

The decrease in cytosolic free calcium results in vasodilatation of the coronary and systemic arteries. ${ }^{7}$

Several risk factors are associated with the occurrence of Ischemic heart disease. Those include tobacco use, diabetes, high blood pressure, high blood cholesterol or triglyceride level, history of heart disease, older age, lack of exercise, stress and obesity. ${ }^{8}$ Obesity raises the risk of angina and heart disease because it's associated with high blood cholesterol levels, high blood pressure and diabetes. Also, in obese person heart has to work harder to supply blood to the excess tissue. ${ }^{8}$

Earlier studies revealed that obesity is associated with hyperlipidemia in different age groups. Hypertriglyceridemia and hypercholesterolemia being the most common forms of lipid abnormality found in those groups of the population. ${ }^{9,10}$ Both forms of lipid abnormalities and obesity appear to be risk factors for angina. ${ }^{8}$

To counteract hypercholesterolemia in angina patients, statins are always used as first line drugs. However, statin toxicities are of real concern rendering this drug to be kept under the constant radar. ${ }^{11}$

There are various options available to counteract obesity which include both pharmacological and nonpharmacological interventions. All weight-loss programs require changes in eating habits and increased physical activity. The treatment methods that are right for a person depends on the level of obesity, overall health and willingness to participate in the weight-loss plan. ${ }^{12}$

Other treatment tools include dietary changes, exercise and activity, behavior change, Prescription weight loss medications and Weight-loss surgery. ${ }^{12}$

Prescription weight-loss medications (also called as antiobesity drugs) are used more frequently these days than ever before. ${ }^{13}$ This is particularly of more concern when a patient is already placed on multi-drug cocktail for his other concomitant health conditions. Since most of the patients with angina are obese, it is likely to see that they are taking multiple drugs for their conditions. This not only leads to huge economic burden but also exposes the patient to unnecessary side effects and potential drugdrug interactions on short and long term basis. Hence there is a need for the development of a new drug which would work against both angina and obesity. This will not only reduce cost burden but also the occurrence of side effects and possible short and long term drug- drug interactions as compared to multidrug therapy.

The previous study shows that 3 weeks administration of nicorandil reduces body weight in rats. ${ }^{14}$ The purpose of conducting our current study is to reconfirm the finding of the previous study. Since our study was conducted on 2 different animal species (albino rabbits and albino mice) rather than single one, therefore, we expect that the outcomes would carry high authenticity and good reproducibility on other species.

\section{METHODS}

The current study was approved by the Institutional Ethical Committee for animal experimentations. For this study, we selected 30 adult albino rabbits (each having one to one and a half $\mathrm{Kg}$ body weight) and 30 albino mice (each having 20 to 25 grams body weight) with male/female ratio of 1:1. All animals were maintained at optimum room temperature in a well-ventilated animal house under natural photoperiod conditions. Each species of animal was divided into five groups, having six in every group with a male-female ratio of $1: 1$. The administration was affected in a volume of $5 \mathrm{ml} / \mathrm{kg}$ and $20 \mathrm{ml} / \mathrm{kg}$ body weight for rabbits and mice respectively. ${ }^{15}$ Weight of study animals was measured by Detecto's Electronic veterinary weighing scale. The initial study revealed that the body weight measurement technique in both species was reliable and consistent.

To observe the chronic effect, we administered graded doses of nicorandil in the respective test groups once a day for a period of 4 weeks. Administration of drug was made effective at 9 AM every day.

In contrary, the control group was treated with normal saline of equal volume to the testing drug doses. The time for administration of normal saline was essentially the same as drug administration i.e. 9 AM. Route of administration in all groups was an intraperitoneal (IP) injection.

Measurement of body weight of all groups of the animal was done by the end of every week (on Saturdays) for 4 weeks (entire study period). The mean body weight of post-treatment group was compared with respective pretreatment group in every week for a period of 4 weeks and the results were interpreted. 
Nicorandil for this study was obtained in the form of injection IKOREL (Rhone-Poulenc). The range of plasma concentrations of Nicorandil in human at therapeutic doses is similar to that of experimental models in which the $\mathrm{k}(+)$ channel activity has been determined. ${ }^{16}$ So the dose of nicorandil for this study was determined as per this study.

\section{Statistical analysis}

All the results were expressed as mean \pm SD. Student Ttest was used to assess the statistical significance of results before and after administration in both control (saline treated) and drug (nicorandil) treated groups. The $\mathrm{P}$ value $<0.05$ was considered as significant, and $\mathrm{P}$ value $>0.1$ as insignificant.

\section{RESULTS}

In rabbits; administration of graded doses of Nicorandil caused lowering of body weight with a dose range between 128 to $512 \mathrm{mcg} / \mathrm{kg}$ body weight on most occasions. Such fall in body weight was significant by the end of the $4^{\text {th }}$ week with a dose range of $128-512 \mathrm{mcg} / \mathrm{kg}$ body weight (Table 1)

In mice; administration of graded doses of Nicorandil caused lowering of body weight with a dose range between 128 to $512 \mathrm{mcg} / \mathrm{kg}$ body weight on most occasions. Such fall in body weight was significant by the end of the $4^{\text {th }}$ week (Table 2 ).

Table 1: Effect of chronic administration (for 28 days) of nicorandil on body weight of albino rabbit.

\begin{tabular}{|c|c|c|c|c|c|c|c|c|c|c|c|c|}
\hline \multirow{3}{*}{$\begin{array}{l}\text { Name of } \\
\text { drug }\end{array}$} & \multirow{3}{*}{$\begin{array}{l}\text { Dose } \\
\text { (Unit/kg) } \\
\text { (IP) }\end{array}$} & \multirow{3}{*}{$\begin{array}{l}\text { No. of } \\
\text { rabbits }\end{array}$} & \multicolumn{5}{|c|}{ Mean body weight (in kgs) \pm SEM* } & \multirow{2}{*}{\multicolumn{4}{|c|}{$\begin{array}{l}\text { Difference showing the trend } \\
\text { in reduction of mean weight } \\
\text { at successive weeks }\end{array}$}} & \multirow{3}{*}{$\begin{array}{l}\text { P } \\
\text { value } \\
\text { (at } \\
\text { the } \\
\text { end of } \\
\text { study) }\end{array}$} \\
\hline & & & \multirow{2}{*}{$\begin{array}{l}\text { Before } \\
\text { drug } \\
\text { (a) }\end{array}$} & \multicolumn{4}{|c|}{ After drug (in weeks) } & & & & & \\
\hline & & & & $\mathbf{1}^{\text {st }}(\mathbf{b})$ & $2^{\text {nd }}(c)$ & $3^{\text {rd }}(d)$ & $4^{\text {th }}(e)$ & $\begin{array}{l}1^{\text {st }} \\
(\mathbf{a}-\mathbf{b})\end{array}$ & $\begin{array}{l}2^{\text {nd }} \\
(a-c)\end{array}$ & $\begin{array}{l}3^{\text {rd }} \\
(\mathbf{a}-d)\end{array}$ & $\begin{array}{l}4^{\text {th }} \\
(a-e)\end{array}$ & \\
\hline Nicorandil & $8 \mathrm{mcg}$ & 6 & $\begin{array}{l}1.220 \pm \\
0.052 \\
\end{array}$ & $\begin{array}{l}1.212 \pm \\
0.048 \\
\end{array}$ & $\begin{array}{l}1.224 \pm \\
0.053\end{array}$ & $\begin{array}{l}1.210 \pm \\
0.049\end{array}$ & $\begin{array}{l}1.216 \pm \\
0.051\end{array}$ & 0.008 & $\begin{array}{l}- \\
0.004\end{array}$ & 0.01 & 0.004 & $>0.1$ \\
\hline Nicorandil & $32 \mathrm{mcg}$ & 6 & $\begin{array}{l}1.304 \pm \\
0.105\end{array}$ & $\begin{array}{l}1.314 \pm \\
0.103\end{array}$ & $\begin{array}{l}1.306 \pm \\
0.104\end{array}$ & $\begin{array}{l}1.300 \pm \\
0.111\end{array}$ & $\begin{array}{l}1.292 \pm \\
0.104\end{array}$ & $\begin{array}{l}- \\
0.01\end{array}$ & 0.002 & 0.004 & 0.012 & $>0.1$ \\
\hline Nicorandil & $128 \mathrm{mcg}$ & 6 & $\begin{array}{l}1.40 \pm \\
0.158\end{array}$ & $\begin{array}{l}1.372 \pm \\
0.122\end{array}$ & $\begin{array}{l}1.318 \pm \\
0.146\end{array}$ & $\begin{array}{l}1.228 \pm \\
0.162\end{array}$ & $\begin{array}{l}1.193 \pm \\
0.149\end{array}$ & 0.028 & 0.082 & 0.172 & 0.207 & $<0.05$ \\
\hline Nicorandil & $512 \mathrm{mcg}$ & 6 & $\begin{array}{l}1.320 \pm \\
0.114\end{array}$ & $\begin{array}{l}1.318 \pm \\
0.110\end{array}$ & $\begin{array}{l}1.232 \pm \\
0.112\end{array}$ & $\begin{array}{l}1.167 \pm \\
0.122\end{array}$ & $\begin{array}{l}1.172 \pm \\
0.106\end{array}$ & 0.002 & 0.088 & 0.153 & 0.148 & $<0.05$ \\
\hline $\begin{array}{l}\text { Normal } \\
\text { Saline }\end{array}$ & $5 \mathrm{ml}$ & 6 & $\begin{array}{l}1.250 \pm \\
0.050\end{array}$ & $\begin{array}{l}1.252 \pm \\
0.054\end{array}$ & $\begin{array}{l}1.250 \pm \\
0.056\end{array}$ & $\begin{array}{l}1.250 \pm \\
0.055\end{array}$ & $\begin{array}{l}1.255 \pm \\
0.058\end{array}$ & 0.002 & 0 & 0 & 0.005 & $>0.1$ \\
\hline
\end{tabular}

SEM* Standard Error of Mean

Table 2: Effect of chronic administration (for 28 days) of nicorandil on body weight of albino mice.

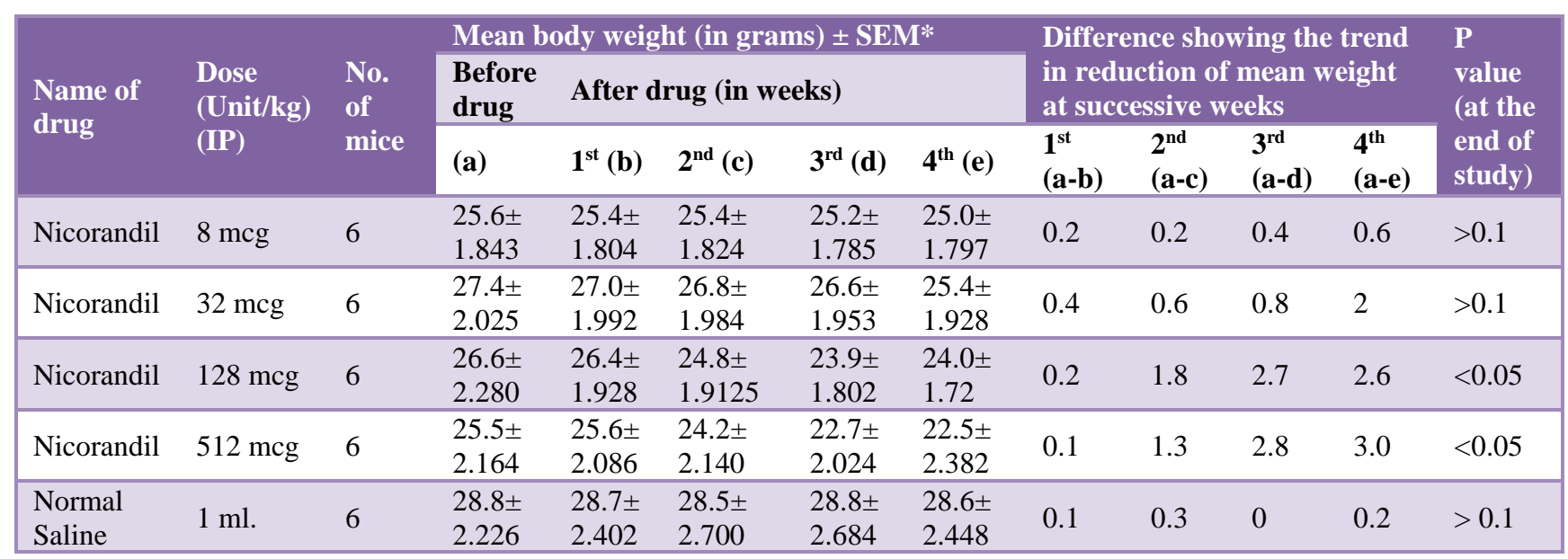

SEM* Standard Error of Mean

\section{DISCUSSION}

Chronic administration of Nicorandil (for a period of 4 weeks) reduced body weight with a dose range between $128-512 \mathrm{mcg} / \mathrm{kg}$ body weight at most occasions. This 
trend in the reduction of body weight was consistent in both species. Such reduction in body weight was statistically significant by the end of 4 th week $(\mathrm{P}<0.05)$ with a dose of $512 \mathrm{mcg} / \mathrm{kg}$ body weight in both species of study animal (Table 1 and 2).

However, there was minimal/ no change in body weight in either species during the $1^{\text {st }}$ and $2^{\text {nd }}$ weeks of nicorandil administration (graded doses).

The study also revealed that the major reduction in body weight was more evident between the $2^{\text {nd }}$ and $3^{\text {rd }}$ weeks with slight or no effect after that until the end of the study period (ceiling effect).

The above findings are in contrast with the outcome of a previous study which revealed that 3 weeks administration of nicorandil significantly increases body weight of monocrotaline administered rats. ${ }^{14}$

This ceiling effect was noticed with a dose range of 128$512 \mathrm{mcg} / \mathrm{kg}$ body weight in both species. The reason behind such effect could be as a result of physiological adaptation to weight loss favouring weight regain. Some compensatory drive includes but not limited to; altered levels of circulating appetite-related hormones, energy balance, nutrient metabolism, one's appetite and basal metabolic rate. ${ }^{17}$

Our study was conducted on two different species rather than single one, and the outcome of the study in both species was identical. Therefore, there's a higher possibility of duplicating similar sort of findings if the study is carried out on other species including human beings. $^{18}$

The current study reflects that nicorandil reduces body weight in two different species (in a dose-dependent manner) when administered on a long-term basis (more than 3 weeks). Body weight reducing effects of nicorandil persisted up to 4 weeks with a ceiling effect in the last week. If such findings are successfully supported by clinical studies, it will open the door for new possibility to rationalize this drug for treating patients suffering from concomitant angina and obesity.

On the other hand, the ceiling effect of nicorandil in reducing body weight, if approved in humans, could appear as a limiting factor to prescribe this drug on long term basis for the treatment of obesity.

Body weight reducing property of nicorandil in animals' if established in human could enhance its acceptability in certain clinical conditions like obesity with ischemic heart disease.

The ceiling effect of nicorandil appears to be a distinct disadvantage for its use to treat obesity on the long-term basis. Moreover, the current study was conducted using a limited number of samples. Further studies involving bigger samples in both experimental and clinical setting are needed to confirm the rationality of using nicorandil in patients suffering from obesity with ischemic heart disease.

\section{Funding: No funding sources \\ Conflict of interest: None declared \\ Ethical approval: The study was approved by the Institutional Ethics Committee}

\section{REFERENCES}

1. Ford I. Impact of nicorandil in angina: subgroup analyses. Heart 2004;90(12):1427-30.

2. Aizawa T, Ogasawara K, Kato K. Effects of Nicorandil on Coronary Circulation in Patients with Ischemic Heart Disease. Journal of Cardiovascular Pharmacology. 1987;10:123-9.

3. Frampton J, Buckley M, Fitton A. Nicorandil. Drugs 1992;44(4):625-55.

4. Purcell H, Fox K. Potassium channel openers in myocardial ischemia - clinical experience with nicorandil. Journal of Clinical and Basic Cardiology. 1999;2(1):12-4.

5. Essentials of Medical Pharmacology. $5^{\text {th }}$ Ed. Delhi, India: Jaypee; 2004:498.

6. Kukovetz W, Holzmann S, Pöch G. Molecular Mechanism of Action of Nicorandil. Journal of Cardiovascular Pharmacology. 1992;20:1-7.

7. Kinoshita, M, Sakai, K. Pharmacology and therapeutic effects of nicorandil. Cardiovascular Drugs and Therapy. 1990;4(4):1075-88.

8. Mayo Clinic. Angina Risk factors: Angina, 2017. Available at: http://www.mayoclinic.org/diseasesconditions/angina/basics/risk-factors/con-20031194. Accessed 25 Apr. 2017.

9. Lai, $\mathrm{S}, \mathrm{Nq} \mathrm{K}$, Lin H, Chen H. Association between obesity and hyperlipidemia among children. Yale J Biol Med. 2001;74(4):205-10.

10. Gostynski M, Gutzwiller F, Kuulasmaa K, Döring A, Ferrario M, Grafnetter D, et al. Analysis of the relationship between total cholesterol, age, body mass index among males and females in the WHO MONICA Project. International Journal of Obesity. 2004;28(8):1082-90.

11. Golomb B, Statin EM. Adverse Effects. American Journal of Cardiovascular Drugs. 2008;8(6):373-418.

12. Mayo Clinic. Obesity Treatments and drugs, 2017. Available at: http://www.mayoclinic.org/diseasesconditions/obesity/basics/treatment/con-20014834. Accessed 25 Apr. 2017.

13. Stafford R, Radley D. National Trends in Antiobesity Medication Use. Archives of Internal Medicine. 2003;163(9):1046.

14. Zuo X, Wang Q, Cao Q, Yu Y, Wang H, Bi L, et al. Nicorandil Prevents Right Ventricular Remodeling by Inhibiting Apoptosis and Lowering Pressure Overload in Rats with Pulmonary Arterial Hypertension. PLoS ONE. 2012;7(9):44485. 
15. Diehl K, Hull R, Morton D, Pfister R, Rabemampianina Y, Smith D, et al. A good practice guide to the administration of substances and removal of blood including routes and volumes. Journal of Applied Toxicology. 2001;21(1):15-23.

16. Krumenacker M, Roland E. Clinical profile of nicorandil: an overview of its hemodynamic properties and therapeutic efficacy. J Cardiovasc Pharmacol. 1992;20(3):93-102.

17. Greenway F. Physiological adaptations to weight loss and factors favouring weight regain. International Journal of Obesity. 2015;39(8):1188-96.
18. Aguilar-Nascimento, J. Fundamental steps in experimental design for animal studies. Acta Cirurgica Brasileira. 2005;20(1).

Cite this article as: Das S, Alsalhanie KM, Nauhria S, Datta AN. Effect of chronic administration of nicorandil (a potassium channel activator) on body weight of two different experimental animal species. Int J Basic Clin Pharmacol 2017;6:1567-71. 